\title{
Mathematical Modeling of Waste Engine Oil Gasification for Synthesis Gas Production; Operating Parameters and Simulation
}

\author{
Mohammad Rasoul Mousazade ${ }^{1}$, Mehdi Sedighi ${ }^{2}$, Mohammad Hasan Khoshgoftar Manesh ${ }^{3,4}$, Mostafa \\ Ghasemi $^{5}$ \\ 1* Division of Thermal Sciences and Energy Systems, Department of Mechanical Engineering, Faculty of Technology \& \\ Engineering, University of Qom, Qom, Iran \\ ${ }^{2}$ Department of Chemical Engineering, University of Qom, Qom, Iran \\ ${ }^{3}$ Energy, Environment and Biological Systems Research Lab (EEBRlab), Division of Thermal Sciences and Energy \\ Systems, Department of Mechanical Engineering, Faculty of Technology \& Engineering, University of Qom, Qom, Iran \\ ${ }^{4}$ Center of Environmental Research, University of Qom, Qom, Iran \\ ${ }^{5}$ Chemical Engineering section, Sohar University, Sohar, 311, Oman \\ E-mail: ${ }^{2}$ sedighi@qom.ac.ir
}

Received 19 June 2021, Revised 8 September 2021, Accepted 13 October 2021

\begin{abstract}
The release of waste oil into the environment will have destructive effects. Gasification is an advanced and environmentally friendly process for converting waste oils into clean combustible gas products. Thermochemical equilibrium modeling has been used in this method to predict the performance of a downdraft gasifier. This model uses the thermodynamic equilibrium of gasification reactions to predict the gases produced in the gas mixture. Having the percentage of gas components produced, different characteristics of the produced gas including $\mathrm{H}_{2}: \mathrm{CO}$ ratio, process temperature and calorific value of the produced gas, Cold gas efficiencies and carbon conversion efficiency are also obtained. The effect of equivalence ratio, oxygen enrichment and pressure on gasification properties is analyzed. The simulation results are compared with the reported experimental measurements through which the numerical model is confirmed. The results indicated that the equivalence ratio (mole of air in gasification per mole of air in combustion) between 0.4 and 0.42 had the potential to yield the highest calorific value about $10.5 \mathrm{Mj} . \mathrm{m}^{-3}$. The temperature of gaseous mixture in this range will be $2000 \mathrm{~K}$ that can be used for other processes such as steam generation. Using pure oxygen instead of air reduces the efficiency of the gasifier from $78 \%$ to $55 \%$. Pressure changes from 10 to 65 bar cause gas mixture temperature changes from 1684 to 1690 Kelvin. The $\mathrm{H}_{2}: \mathrm{CO}$ ratio decreases from 1.6 to 0.6 with increasing equivalence ratio and increases from 1.2 to 1.6 with changes in oxygen enrichment.
\end{abstract}

\section{Keywords: Gasification; waste engine oil; chemical equilibrium; syngas production; numerical modeling.}

\section{Introduction}

Internal combustion engines need lubricating oils to operate. The increasing use of internal combustion engines has led to an increase in the amount of waste oil (WLO) worldwide. The production of waste lubricating oil is estimated at 24million tons annually worldwide [1]. and 45 million gallons per year in Florida alone [2]. About $60 \%$ of the lubricating oil produced is converted into waste oil [3]. Lubricating oils are used to reduce friction and wear between rotating engine components [4]. Lubricating oil is one of the distillation parts of crude oil, but joinery brands are obtained in a mixture [5]. This oil is composed of a large number of organic compounds and some heavy metals $[6,7]$. Viscosity is considered as the most important property of lubricating oil [8]. Over time, lubricating oils lose their viscosity and become unsuitable for use in the engine [9]. The chemical composition of used lubricating oil varies widely and depends on the original crude oil, the refining processes, the efficiency of engine that used the oil and to the original oil, and the duration of use of engine oil. Lube oils are designed to withstand very high service temperatures in the internal combustion engines and resist thermal degradation [2].
Elemental analysis of a sample of waste engine oil indicated 13.28 wt.\% hydrogen (See Table 1) content. It is twice the hydrogen available in wood biomass and about three weight percent heavier than vegetable oils. The high amount of hydrogen content in waste engine oil makes it a valuable raw material for hydrogen production. Releasing WLO into the environment poses a peril to it. The study of recycling and reuse techniques is not only an effort to recover energy but also a struggle for environmental sustainability. WLOs can also be used as raw materials for the thermochemical conversion process to produce useful products. Such processes include pyrolysis and gasification [10]. The use of lubricating oil as a raw material for hydrogen production is desirable because it is cheap and available throughout the year [2]. Used oil is available all year round without any seasonal fluctuations at a relatively low cost for example typically 10 cents/gallon delivered in Florida [2]. The gasification process is a partial thermal oxidation, Which leads to gaseous products (carbon dioxide, hydrogen, carbon monoxide, water vapor, methane and other gaseous hydrocarbons) and small amounts of coal, ash and condensable compounds [11]. The quality of gas produced 
from gasification varies as a function of the gasifier agent (air, oxygen, steam, carbon dioxide or a mixture of them) and operating conditions. Installing small, low-cost, and efficient gasifier-engine systems can be an attractive alternative to direct combustion, taking into account achievable electrical efficiency and storage and transportation costs [12]. The produced gas, after cleaning and air conditioning, can be used as fuel in gas engines and turbines due to its acceptable thermochemical combustion properties (flame speed and knock tendency) [13]. Gasification is also considered as a cleaner and more efficient technology than combustion, because it enables higher electrical functions on a smaller scale and due to its very acceptable combustion properties combined with a typical Rankin cycle [14], less $\mathrm{NO}_{\mathrm{X}}$ and $\mathrm{SO}_{\mathrm{X}}$ emissions, And the possibility of $\mathrm{CO}_{2}$ capture [15].

However, gasification must overcome a number of obstacles to commercialization. Important issues such as the removal of particles in the exhaust gas, issues related to the production and pre-treatment of biomass raw materials, while in the case of waste oil this cost is less. In order to optimize the gasification process, a better understanding of the effect of inlet fuel properties and parameters of gasification operation on the quality of gas produced and gasification performance is required [16]. Therefore, it is necessary to discover and understand the main mechanisms of gasification. As a result, simulation of gasification processes is required for scaling, industrial control strategies, and performance evaluation after modifying the operating conditions [17]. Compared to the direct construction of experimental units, mathematical modeling of a gasification process is a relatively quick and economical solution. Mathematical models, based on theoretical and experimental work and practical operations are used for the purpose of analyzing thermochemical processes during gasification and evaluating the effect of the main input variables on the properties of gas products (i.e., gas composition and calorific value) [17]. Different kinds of models have been developed for gasification systems, including computational fluid dynamic (CFD), artificial neural networks (ANN), thermodynamic equilibrium and kinetic models [18].

The comparison of different mathematical models showed that the thermodynamic equilibrium model, is the simplest and can be used as an effective primary tool to analyses the effect of process parameters and different fuel types on a gasification process. Thermodynamic equilibrium model, opposing to kinetic, ANN and CFD models, are characterized by a higher level of flexibility and applicability. Moreover, less computational intensity is required in a thermodynamic equilibrium model [19]. These models calculate the composition at the highest stability of the products of a reaction, a condition defined as thermodynamic equilibrium which is met at the level of the products minimum chemical potential [20]. In practice, the lack of ideal conditions along with design restrictions, e.g. retention time, prevent the output products to reach thermodynamic equilibrium [21]. In this regard, these models usually overestimate the yields of $\mathrm{H}_{2}$ and $\mathrm{CO}$, underestimate those of $\mathrm{CO}_{2}$, and predict an outlet stream free from $\mathrm{CH}_{4}$, tars, and charcoal. Nonetheless, thermodynamic equilibrium calculations, which are also independent of gasifier design, may provide useful insights, e.g. the influence of the most important process parameters. Further, the long residence time needed in fixed bed gasifiers suggest that the process propagate at a rather slow rate while the producer gas composition in practice ends up not too far from equilibrium [22]. For fluidized bed gasifiers, the average bed temperature can be used as the process temperature, whereas for downdraft gasifiers, the outlet temperature at the throat exit should be used [23].

Sharma et al. [24] examined how changes in humidity, pressure, equivalence ratio, and initial reactor temperature affected exhaust gas components, calorific value, temperature, and efficiency of gasification. Shen et al. [25] used Aspen Plus for biomass gasification modeling and investigated the optimal hydrogen production conditions. Mountouris et al. [26] focused on modeling Plasma gasification using constant equilibrium equations and the soot formation in the output products and investigated the effect of gasification parameters on solid waste gasification. Jarungthammachote et al. [27] used a thermodynamic equilibrium model based on the equilibrium constant to investigate the gases produced from the downdraft gasification process and investigated the effect of biomass moisture on the mole fraction of the gaseous components. Ashizawa et al. [28] studied experimentally the effect of various parameters such as an equivalence ratio, cold gas efficiency, calorific value of the produced gas and the exhaust gas mixture composition in a pilot downdraft gasifier. Beheshti et al. [29] used thermodynamic modeling to evaluate waste lubricating oil's gasification by minimizing the Gibbs free energy and these parameters in the gasification process: pressure, inlet vapor and equivalence ratio. Beheshti et al. [30] presented a mathematical equations for modeling the catalytic steam gasification of heavy oil, aiming to investigate the effect of gasification temperature, gasification pressure, steam to fuel ratio and the ratio of catalyst to fuel on the volume percentage of exhaust gas mixture's components. By using a thermodynamic equilibrium model, Khaleghi et al. [31] studied mazut gasification a heavy fuel oil with a high percentage of sulfur, assessed it's equivalence ratio and investigated the use of steam as a gasification agent. Santiago et al. [32] studied thermochemical conversion as an alternative oil sludge process and explored various gasifying agent's effects on syngas properties. The downdraft gasifier and gas engine with industrial olive oil was studied by Vera et al. [33]. Results indicated such system's ability to ensure power efficiency of $14 \%$, the overall efficiency of $36 \%$, and high gasification efficiency. Sanchez-Hernandez et al. [34] focused on different options to upgrade engine oils by gasification using steam and supercritical water. This method converts more than $85 \%$ of oil into valuable gases. Couto et al. [35] performed numerical and experimental modeling of municipal solid waste gasification process analysis. A two-dimensional multiphase model has been integrated with chemical reactions for the gasification process. The Computational Fluid Dynamic (CFD) Fluent framework has been used to develop the numerical model. Ruggiero and Manfrida. [36] presented a simple model for biomass gasification considering the Gibbs free energy and emphasizing the potential of using the equilibrium model. Melgar et al. [37] Modeled biomass gasification and investigated the effect of moisture content in biomass and the effect of air to fuel ratio on the adiabatic temperature of gasification, distribution of production gas components and gasification efficiency.

Prins et al. [23] investigated The gasification process with a chemical equilibrium model and showed that the equilibrium model indicates the highest gasification efficiency that can be achieved for a fuel. Altafini and 
Mirandola. [38] studied coal gasification based on chemical equilibrium using Gibbs free energy minimization method. It has also studied the concentration of gases produced and the efficiency of gasification and the efficiency of carbon conversion. Their studies show that the results of chemical modeling are close to the experimental results.

Lapuerta et al. [39] used a chemical equilibrium model to predict the concentration of gases produced in gasification as a function of fuel to air ratio. Schuster et al. [40] proposed a model for the study of biomass steam gasification in the Fluidized bed gasification. Their model includes two zones, one zone for gasification by steam and other for combustion, so that the concentration of gases produced is estimated by an equilibrium model using the Gibbs free energy minimization method. This model investigates the effect of operational parameters such as moisture in biomass, gasification temperature and gasification agent on the concentration of gases produced, their calorific value and process efficiency. Jayah et al. [41] proposed a model for two regions, gasification and pyrolysis for the downstream gasification. In the pyrolysis section, the composition of the produced gas mixture and its temperature are estimated by chemical equilibrium. The output results of the first zone will obtain the input information of the second zone. In this area, it is assumed that the carbon components do not react to the bottom of the gas generator and move vertically. This model estimates the temperature changes, the composition of the components of the produced gas mixture and carbon conversion efficiency. This model is in good agreement with the experimental data in the downstream gasifier. In this model, sensitivity analysis is performed on different biomass sizes, changes in biomass humidity, air inlet temperature, and heat loss. The result of this analysis is to obtain the optimal length of the gasifier in order to increase the efficiency of biomass to gas conversion. Di Blasi. [42] has considered a dynamic one-dimensional model in the solid phase and the gas phase for the downstream gas generator. Such things as water evaporation, pyrolysis, combustion and carbonation of carbon in biomass, gas phase combustion and heat transfer during gasification also effect of air to fuel ratio on efficiency of the gasification process and the concentration of exhaust gases and their quality. Rao et al. [43] investigated the irreversibility of a downdraft gasifier and evaluated it for various biomasses.

The novelty of the work is to apply a systematic approach using thermodynamic concepts to model and simulate the gasification process of waste engine oil using mathematical equations. The results of the simulation were compared with the experimental data with high accuracy. After validation, the results used the model to predict the gasifier's behavior in the gasification of waste oils. Furthermore, the sensitivity analysis of main parameters and operating conditions were investigated.

\section{Mathematical modeling}

In order to establish the chemical equilibrium, sufficient time is taken for the reactions to take place, so the effect of the velocity factor on the reactions will not be considered. gasification products will be only gaseous components and carbon components remain. Exhaust gas mixture includes hydrogen, carbon monoxide, carbon dioxide, methane, water vapor, and nitrogen. Gaseous components such as nitrogen oxides, sulfur oxides have been eliminated due to their very small amount in the experimental results.
The gasification process operates at constant pressure. The heat transfer rate from the gasification reactor is $6 \%$ of the fuel's high calorific value in the dry state. The produced gas mixture and its components are assumed to be ideal gas. The general equation of gasification is as follows:

$$
\begin{aligned}
\mathrm{CH}_{\alpha} \mathrm{O}_{\beta} \mathrm{N}_{z}+w \mathrm{H}_{2} \mathrm{O} & +\mathrm{SH}_{2} \mathrm{O} \\
+ & m\left(\mathrm{O}_{2}+3 \text { ? } 76 \mathrm{~N}_{2}\right) \\
& \rightarrow x_{1} \mathrm{H}_{2}+x_{2} \mathrm{CO}+x_{3} \mathrm{CO}_{2} \\
& +x_{4} \mathrm{H}_{2} \mathrm{O}+x_{5} \mathrm{CH}_{4} \\
& +\left(\frac{z}{2}+3.76 m\right) \mathrm{N}_{2}+x_{6} \mathrm{C}
\end{aligned}
$$

$\mathrm{w}, \mathrm{s}, \mathrm{m}, \mathrm{x}_{1}$ to $\mathrm{x}_{5}$ and $\mathrm{x}_{6}$ are mole of moisture per one mole of fuel, mole of steam, mole of air that is needed in gasification, mole number of gaseous productions and mole number of carbon respectively. Extra equations of gasification modeling are in Appendix A. The final equations will have six unknowns in the presence of carbon in the output products and five unknowns in its absence. To find all of them, chemical equilibrium constant equations are needed. To model the gasification process, five key reactions have been considered, three of which contain the carbon component and the other two contain no carbon. The equilibrium constant of these reactions and the relevant equations for finding equilibrium constants are in Appendix A.

$$
\begin{aligned}
& \mathrm{C}+\mathrm{CO}_{2} \leftrightarrow 2 \mathrm{CO} \\
& \mathrm{C}+\mathrm{H}_{2} \mathrm{O} \leftrightarrow \mathrm{H}_{2}+\mathrm{CO} \\
& \mathrm{C}+2 \mathrm{H}_{2} \leftrightarrow \mathrm{CH}_{4} \\
& \mathrm{CO}+\mathrm{H}_{2} \mathrm{O} \leftrightarrow \mathrm{H}_{2}+\mathrm{CO}_{2} \\
& \mathrm{CH}_{4}+\mathrm{H}_{2} \mathrm{O} \leftrightarrow \mathrm{CO}+3 \mathrm{H}_{2}
\end{aligned}
$$

Here are two equations of equilibrium constants for water-gas reactions and methane reforming:

$$
\begin{aligned}
& K_{\text {watergas shift }}=\exp (1.86 \ln T-(5.4 \times \\
& \left.\left.10^{-4}\right) \frac{T}{2}+\frac{116400}{2 T^{2}}-18.0173-\frac{-4.8826 \times 10^{4}}{R_{u} T}\right) \\
& K_{\text {steam reforming }}=\exp (7.9510 \ln T- \\
& 0.0087 \frac{T}{2}+\frac{2.1640 \times 10^{-6}}{6} T^{2}-\frac{9700}{2 T^{2}}-24.7515- \\
& \left.\frac{1.8977 \times 10^{5}}{R_{u} T}\right)
\end{aligned}
$$

In real gasification conditions, the reactions do not reach chemical equilibrium due to velocity constraints.

Therefore, the modeling results will deviate slightly from the experimental results. By multiplying the equilibrium constant by coefficients obtained by comparing experimental values and modeling, the amount of this deviation can be reduced by this method by other researchers such as Jurangtamachut et al. [7]. Has also been used. The energy balance equation can be used to find the gasification temperature for this purpose, the following equation will be established: 


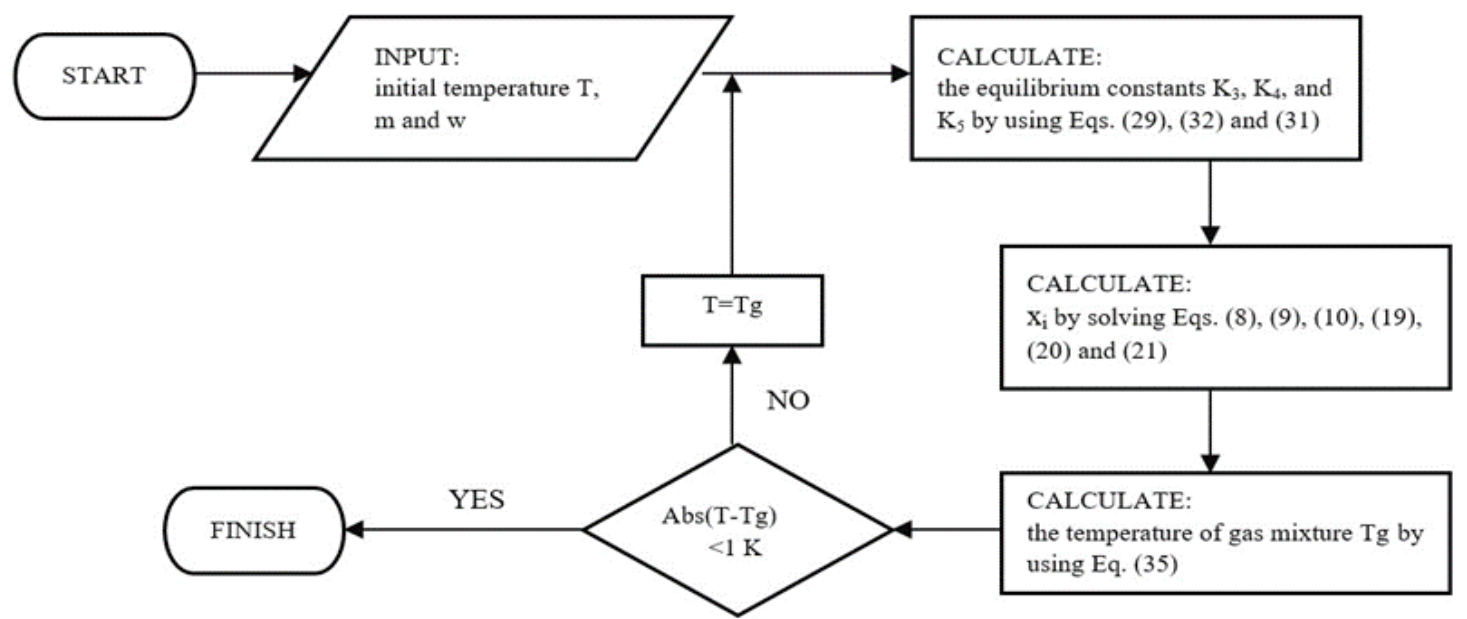

Figure 1. The calculation procedure.

$\sum_{i=\text { reactant }} n_{i}\left(H_{f i}^{0}+\Delta H_{T i}^{0}\right)=$

$\sum_{j=\text { product }} n_{j}\left(H_{f j}^{0}+\Delta H_{T j}^{0}\right)$

Based on the formula, the value of $H_{f}^{0}$ is equal to the standard enthalpy of formation for the reactant and the product. The value of $\Delta H_{T}^{0}$ refers to the enthalpy difference between $298 \mathrm{~K}$ and the gasification temperature, and this value will be zero for reactant since they are at $298 \mathrm{~K}$. The difference in enthalpy of the gaseous components of the product is determined by using Eq. (10)

$\Delta \mathrm{h}=\left(\int_{298}^{\mathrm{T}} \mathrm{C}_{\mathrm{p}} \mathrm{d} T\right)$

$\mathrm{T}$ represents the outlet gasification temperature. A standard enthalpy formation of fuel is derived from this equation [44]:

$h_{\text {fuel }}^{0}=L H V_{\text {fuel }}+\frac{1}{M_{\text {fuel }}} \sum n_{k} h_{f . k}^{0}$

In the above Eq. $n_{k}$ denotes the mole number of gaseous products in the complete combustion of the fuel. $h_{f . k}^{0}$ is the amount of enthalpy of formation of gaseous components in complete combustion. $L H V_{\text {fuel }}$ or lower heating value of fuel can be calculated using the following equation. [27]:

$L H V_{\text {fuel }}=H H V_{\text {fuel }}-m_{h} h_{f g}$

$m_{h}$ denotes the mass fraction of hydrogen in the dry analysis of the fuel and the value of $h_{f g}$ denotes the enthalpy of water vaporization under standard conditions. An experimental equation has been proposed by Chaniwala et al. [44] to estimate the high calorific value of the fuel. This equation is applicable for finding higher calorific value of liquid fuel and was used by some researchers. [29, 30, 45, 46 , 47, 48]:

$$
\begin{aligned}
& H H V_{\text {fuel }}=(0.3491) C+(1.1783) H+(0.1005) S- \\
& (0.1034) O-(0.0151) N-(0.0211) A
\end{aligned}
$$

The coefficients $\mathrm{C}, \mathrm{H}, \mathrm{S}, \mathrm{O}, \mathrm{N}, \mathrm{A}$ represent the mass percentage of carbon, hydrogen, sulfur, oxygen, nitrogen and ash in the dry inlet fuel. These equations are a set of nonlinear polynomial equations that can be solved using the NewtonRaphson method.

This method solves the equations by the process of repetition and using the initial guess. For this purpose, the initial value for gaseous moles and gasification temperature are guessed and by calculating the equilibrium constant, the values of gaseous moles are included in the equations and new values are obtained by solving them, then these new molar values are placed in the energy balance equation For finding new temperature, if the temperature obtained is very slightly different from the initial guess temperature, the solution will be stopped and the answers will be obtained. Otherwise, the new temperature obtained will be replaced by the initial guess temperature and the solution steps will be repeated until The difference between the new temperature and the previous temperature be very small. The coding of these equations is done in MATLAB software, which is a suitable platform for solving mathematical equations. The path of the solution method can be seen as a flowchart in Figure 1.

\section{Results and Discussion}

\subsection{Validation}

This study compared simulation results with the experimental results provided by Ashizawa et al. [28] to validate the simulation. The type of fuel and the operation conditions, like the gasifier pressure and inlet temperature, will be in accordance with the reference article and after validation the type of fuel will be changed into waste engine oil. General inlet fuel information and dry fuel analysis can be found in Table 1. As the table shows, the percentage of carbon, hydrogen, oxygen and nitrogen in the waste oil is very close to its corresponding values in Orimulsion, so the waste oil fuel can be used in this mathematical modeling [29, 47]. By adding a new fuel to the model, the effective performance parameter such as pressure changes, equilibrium ratio and oxygen enrichment will be investigated.

Table 2 shows that the modeling results are very close to the experimental results, and this indicates the validity of the modeling performed in this paper. The error value is measured by the RMS error, which is shown below: 
$R M S=\sqrt[2]{\left(\frac{\sum_{i=1}^{n}\left(r_{i e x p}-r_{i m o d}\right)^{2}}{n}\right)}$

Table 1. Input fuel information used in the gasification process.

\begin{tabular}{ccc}
\hline Proximate Analysis & $\begin{array}{c}\text { Waste lube } \\
\text { oil[49]. }\end{array}$ & Orimulsion[28]. \\
\hline Water content & $0.62 \%$ & $28.8 \%$ \\
Ash & $1.46 \%$ & $0.18 \%$ \\
Residual carbon & - & $12.84 \%$ \\
Total-sulfur & - & $2.81 \%$ \\
HHV & $53.716 \mathrm{MJ} . \mathrm{kg}^{-1}$ & $29.76 \mathrm{MJ}^{-1} \mathrm{~kg}^{-1}$ \\
Ultimate analysis & & \\
(Dry) & & \\
Ash & $1.46 \%$ & $0.25 \%$ \\
$\mathrm{C}$ & $81.27 \%$ & $84.28 \%$ \\
$\mathrm{H}$ & $13.28 \%$ & $10.33 \%$ \\
$\mathrm{O}$ & $1.91 \%$ & $0.55 \%$ \\
$\mathrm{~N}$ & $1.02 \%$ & $0.64 \%$ \\
$\mathrm{~S}$ & $0.56 \%$ & $3.95 \%$ \\
$\mathrm{Cl}$ & $0.05 \%$ & $70 \mathrm{mg} . \mathrm{kg}^{-1}$ \\
\hline
\end{tabular}

In the above expression $r_{\text {imod }}, r_{\text {iexp }}$ and $\mathrm{n}$ represents the molar value of gaseous components in the model, experimental results and the number of gaseous components produced, respectively. According to Jarongtamachut et al.[27], the error in the results achieved by comparing the numerical modeling to experimental results can range between 0.88 to 3.91 . Therefore, the mathematical modeling of waste oil gasification has an acceptable level of error, as presented in Table 2. The waste engine oil is then used as a gasifier inlet fuel. In Table 3 gasification conditions and modeling results for gasification with waste engine oil are investigated. As can be seen, the volume percentage of hydrogen, carbon monoxide and methane gases in the gasification of waste oil is higher than the gasification of orimulsion and the calorific value of the produced gas will be higher.

Table 2. Comparison of modeling and experimental gasification results of Orimulsion [28].

\begin{tabular}{cc}
\hline \multicolumn{2}{c}{ Operating Condition } \\
\hline Equivalence ratio & 0.38 \\
Pressure & $18.75 \mathrm{~atm}$
\end{tabular}

Gasification Agent

Pure Oxygen

Flue Gas Analysis

\begin{tabular}{ccc}
\hline & $\begin{array}{c}\text { Experimental } \\
\text { Results }\end{array}$ & Simulation Results \\
\hline $\mathrm{H}_{2}$ & $39.40 \%$ & $38.82 \%$ \\
$\mathrm{CO}$ & $38.70 \%$ & $40.94 \%$ \\
$\mathrm{CO}_{2}$ & $8.67 \%$ & $7.86 \%$ \\
$\mathrm{H}_{2} \mathrm{O}$ & $11.85 \%$ & $1.25 \%$ \\
$\mathrm{CH}_{4}$ & $0.08 \%$ & $10.90 \%$ \\
$\mathrm{~N}_{2}$ & $0.38 \%$ & $0.16 \%$ \\
$\mathrm{HHV}\left(\mathrm{MJ} . \mathrm{kg}^{-1}\right)$ & $9.5-10.5$ & 10.62 \\
RMS error & & 1.1942 \\
Temperature (K) & 1348 & 1343.6 \\
\hline
\end{tabular}

Table 3. Results of modeling the gasification of waste engine oil.

\begin{tabular}{cc} 
oil. & \\
\hline Operating Condition & 0.38 \\
Equivalence ratio & $18.75 \mathrm{~atm}$ \\
Pressure & Pure Oxygen \\
Gasification Agent & \\
Simulation Results & $42.55 \%$ \\
$\mathrm{H}_{2}$ & $43.42 \%$ \\
$\mathrm{CO}$ & $4.857 \%$ \\
$\mathrm{CO}_{2}$ & $4.85 \%$ \\
$\mathrm{H}_{2} \mathrm{O}$ & $7.713 \%$ \\
$\mathrm{CH}_{4}$ & $0.26 \%$ \\
$\mathrm{~N}_{2}$ & 11.3804 \\
$\mathrm{HHV}\left(\mathrm{MJ}_{\mathrm{Ng}}{ }^{-1}\right)$ & 1390 \\
\hline
\end{tabular}

To evaluate the performance of gasification, equivalence ratio, oxygen enrichment and pressure change of gasification are studied. Equivalence ratio is the ratio of oxygen or air required for gasification to the ratio of oxygen or air required for complete combustion:

$\mathrm{M}=\frac{\text { Oxygen gasification }}{\text { Oxygen combustion }}$

The parameters studied in the gasification process are: temperature, percentage of gas mixture components, cold gas efficiency, calorific value of the produced gas and carbon conversion efficiency. First, the effect of changing the equivalence ratio on the parameters of gasification is examined.

\subsection{Equivalence ratio}

In this section, the value of equivalence ratio will change from 0.3 to 0.6 and the molar changes and volume percentage of the produced gases as well as the amount of temperature changes and other gasification characteristics will be examined. Figure 2. shows the amount of change in moles of gaseous produced. The figure shows that the amount of carbon in the gasification process decreases with increasing equivalence ratio and this decrease is almost linear. This reduction in carbon moles can be explained by the equations used to model this process, as the partial combustion rate of the carbon in the fuel increases with increasing value and the production of carbon dioxide and water vapor increases and the temperature of the gas mixture increases and provides suitable conditions for the gasification process. With the increase of heat due to partial combustion of carbon and the endothermic nature of Eq. (2) and (3), these two reactions will take place and the production of carbon monoxide and hydrogen will increase. Eq. (4) is also exothermic, so a small amount of hydrogen is consumed and converted to methane. This describes the small amount of hydrogen reduction and the production of small amounts of methane in Figure 2. As can be seen from Figure 2. by increasing the equivalence ratio, in other words, by increasing the amount of oxygen input, the process will be closer to combustion in which case 


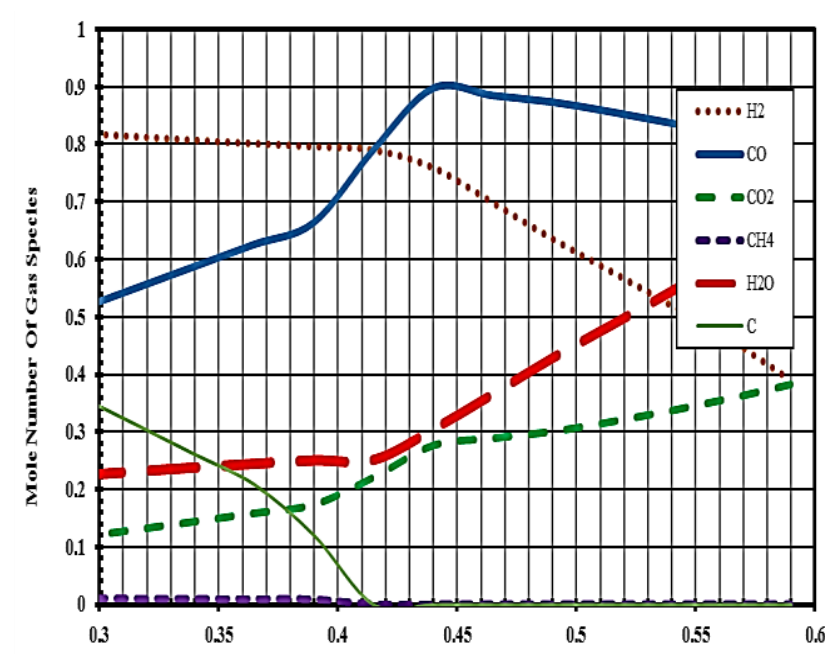

Equivalence Ratio

Figure 2. Changes in the number of moles of gas components produced relative to equivalence ratio (Figure is in color in the on-line version of the paper).

the molar amount of carbon dioxide and water vapor will be increased and the amount of valuable gases carbon monoxide and Hydrogen will be reduced.

Due to the fact that with increasing the equivalence ratio, the gasification process will be closer to the combustion conditions, so the temperature of the gas mixture should increase, which is quite visible in Figure 3. Also, according to this figure, it can be seen that the calorific value of the exhaust gas first decreases and then increases and decreases shortly afterwards This can be explained by the molar changes of the gaseous components that with increasing the equivalence ratio from 0.3 to 0.39 , the mole's number of methane and hydrogen has decreased, which will neutralize the effect of increasing carbon monoxide on the calorific value and reduce it. But by changing the equivalence ratio from 0.39 to 0.415 and by increasing the temperature and performing Eq. (2) and (3), the amount of carbon is completely consumed and the amount of carbon monoxide production increases and will increase the calorific value of the gas mixture.

By increasing the value ratio from 0.415 to 0.6 and approaching the combustion state, the molar number of valuable gases such as hydrogen, carbon monoxide and methane is reduced and the amount of carbon dioxide and water vapor is increased and the high calorific value of the fuel is reduced.

According to Figure 3. the high calorific value of the gas mixture will increase from $10.26 \mathrm{MJ} . \mathrm{m}^{-3}$ in the equivalence

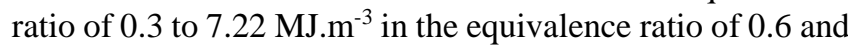

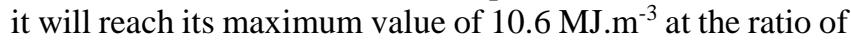
0.415 .

It should also be noted that the calorific value of gas fuel required for combustion in a gas turbine is at least $6 \mathrm{MJ} . \mathrm{m}^{-3}$ [51]. The changes in cold gas efficiency and carbon conversion efficiency that are described below can be seen in Figure 4.

$\eta_{C G}=\left(\frac{E_{p g}}{E_{\text {feed }}}\right) \times 100$

$E_{\text {feed }}=L H V_{\text {feed }} \times M_{\text {feed }}$

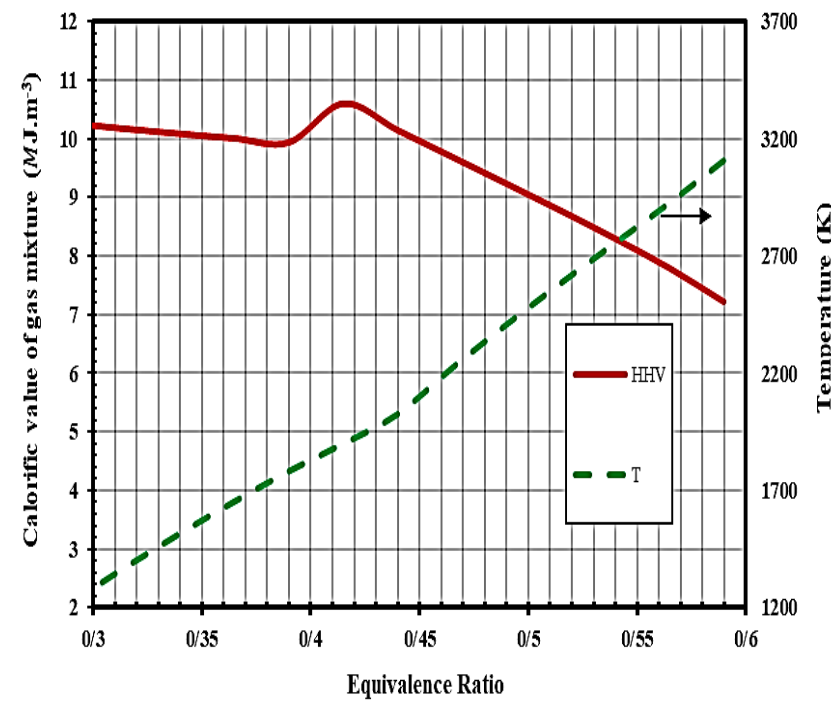

Figure 3. Changes in temperature and calorific value of the gas mixture relative to changes in equivalence ratio (Figure is in color in the on-line version of the paper).

$$
\begin{aligned}
& E_{p g}=n_{\mathrm{H}_{2}} \times\left(h_{\mathrm{H}_{2}}^{0}-h_{\mathrm{H}_{2} \mathrm{O}}^{0}\right)+n_{\mathrm{CO}} \times\left(h_{\mathrm{CO}}^{0}-h_{\mathrm{CO}_{2}}^{0}\right)+ \\
& n_{\mathrm{CH}_{4}} \times\left(h_{C \mathrm{H}_{4}}^{0}-h_{\mathrm{H}_{2} \mathrm{O}}^{0}-h_{\mathrm{CO}_{2}}^{0}\right) \\
& \eta_{C C E}=\frac{12 \times\left(n_{\mathrm{CO}}+n_{\mathrm{CO}_{2}}+n_{\mathrm{CH}_{4}}\right)}{M_{\text {fuel }} \times m_{c}}
\end{aligned}
$$

In the above equations, the value of $n_{i}$ is equal to the molar number of produced gaseous components, $m_{c}$ and $M_{\text {fuel }}$ are the mass percentage of carbon in the dry inlet fuel and the molar mass of the fuel, respectively.

The amount of cold gas efficiency according to Equation (16) is directly dependent on the volume percentage of hydrogen, carbon monoxide and methane. According to the diagram in Figure 4. it is obvious that by changing equivalence ratio from 0.3 to 0.39 , the value of this efficiency increases, although the volume percentage of hydrogen is decreasing in this period, but it should be noted that increasing the amount of carbon monoxide and presence of methane will compensate reduction in hydrogen, so an increase in cold gas efficiency is expected during this period.

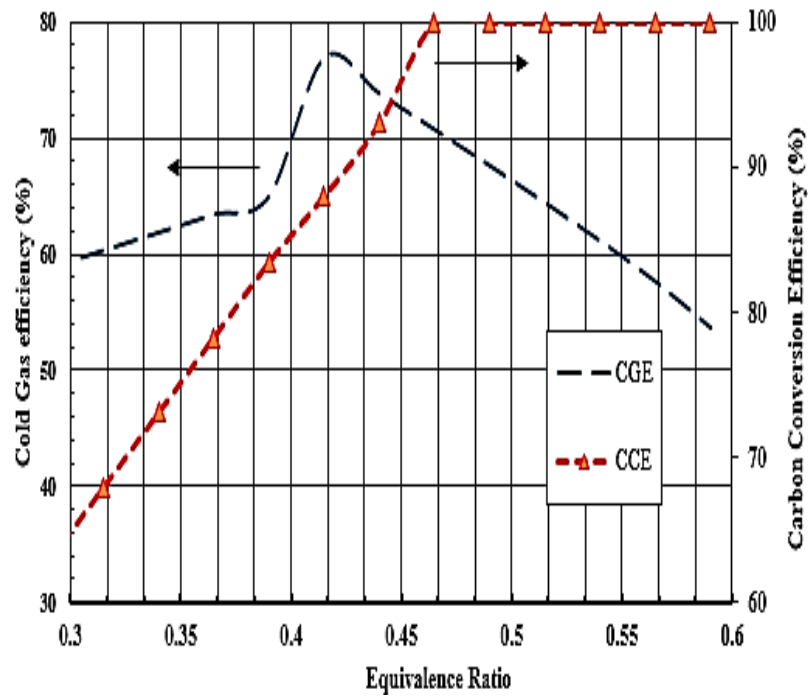

Figure 4. Changes in cold gas efficiency and carbon conversion efficiency relative to equivalence ratio (Figure is in color in the on-line version of the paper). 
In the range of 0.39 to 0.415 , due to the increase in the intensity of carbon-containing reactions, especially Eq. (2) the volume percentage of carbon monoxide will increase significantly which will increase the cold gas efficiency to $77 \%$. It should be noted that with increasing the equivalence ratio, the gasification reaction tends towards combustion and the volume percentage of low value gases such as carbon dioxide and water vapor increases and the amount of carbon monoxide, methane and hydrogen gases that have high calorific value decreases. Therefore, by increasing the equivalence ratio and according to Figure 4 . the cold gas efficiency will be decreased.

\subsection{Oxygen enrichment}

At this stage of modeling, the presence of oxygen in the inlet gasifier will change from its value in normal air $(21 \%)$ to its value in pure oxygen $(100 \%)$ and will cover a wide range of oxygen presence. Next with changes in oxygen enrichment, the amount of changes in gaseous production moles, changes in carbon conversion efficiency, cold gas efficiency changes, volume percentage changes of gas components, temperature changes and changes in high calorific value of the produced gas are investigated. The equivalence ratio is considered to be a constant of 0.35 to take into account the presence of carbon in the production component. The pressure of the gasifier and the temperature of the inlet components to the gasifier are set at a constant value of 18.75 atmospheres and $298 \mathrm{~K}$, respectively. Figure 5 . shows that the number of moles of hydrogen and carbon monoxide gases will increase with decreasing oxygen enrichment and will reach their maximum in the presence of atmospheric air. This can be explained by the equilibrium equations and the energy balance equation. Thus, as the presence of nitrogen gas in the gas mixture increases, the total mole presents in the gas chamber, $\mathrm{n}_{\mathrm{t}}$ will increase and in the energy balance equation, due to the presence of nitrogen gas and heat consumption to change its temperature, a lower temperature will be obtained for the gasifier. Both of these factors will individually affect the chemical equilibrium constants of Eq. (2) and (3) and the molar value of the produced components.

The effect of each of these factors will be discussed with constant consideration of the other factor. In the first stage, it will be assumed that the temperature is constant and the amount of total gas moles increases with the addition of nitrogen gas, in which case the constant amount of chemical equilibrium will remain constant due to the dependence on temperature. In Eq. (2) and (3) with respect to not changing the chemical equilibrium constant and increasing $\mathrm{n}_{\mathrm{t}}$, molar values of carbon monoxide and hydrogen should be increased. In the second stage, the molar amount of nitrogen is considered equal to its amount in atmospheric air and as a result the total gaseous mole will not change much and the chemical equilibrium constant will change as the temperature changes. In this case, due to the presence of nitrogen on the products side in the energy balance, a lower temperature value will be obtained. This decrease in temperature will reduce the equilibrium constants of the two endothermic Eq. (2) and (3) which will affect and reduce the molar number of hydrogen and carbon monoxide gases. By looking at Figure 5. and considering the two steps simultaneously it can be concluded that as oxygen enrichment approaches its presence in atmospheric air, the amount of hydrogen and especially carbon monoxide will be increased. Equation (19), which makes the carbon

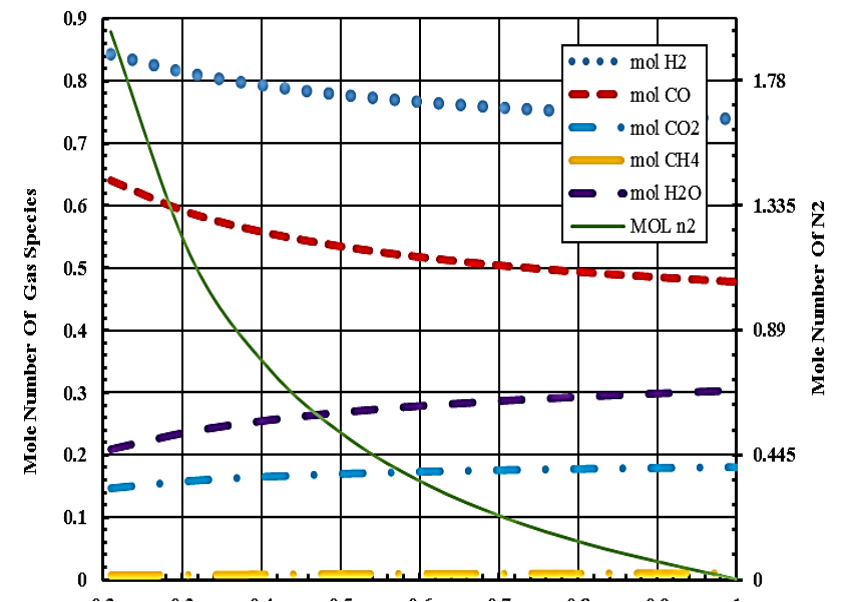

Figure 5. Changè in carbon conversion efficiency and cold gas efficiency relative to changes in input oxygen enrichment (Figure is in color in the on-line version of the paper).

conversion efficiency dependent on the carbon molecules of carbon monoxide, methane and carbon dioxide, this molar increase of carbon monoxide in the gas mixture will increase the carbon conversion efficiency, which can be seen in Figure 6.

This is incorrectly stated in the research of Vaezi et al. [28] in which the increase in carbon conversion efficiency is related to the increase in the volume percentage of carbon dioxide while it is clear that with the decrease of nitrogen in the gas mixture the volume percentage of all components will be increased due to the reduction of the total mole present in the gas chamber and slight change in amount of other gas components. However, according to Figure (5) it is quite understandable that increasing the mole number of carbon monoxide will increase the carbon conversion efficiency and increasing the volume percentage of carbon dioxide has no effect on it. In addition to the above, and according to Eq. (16) to (18), which relate cold gas efficiency to moles of methane, hydrogen and carbon monoxide, it can be expected that by decreasing the moles of these gaseous components due to the increase of oxygen enrichment, Cold gas efficiency will be decreased which can also be clearly seen from Figure 6.

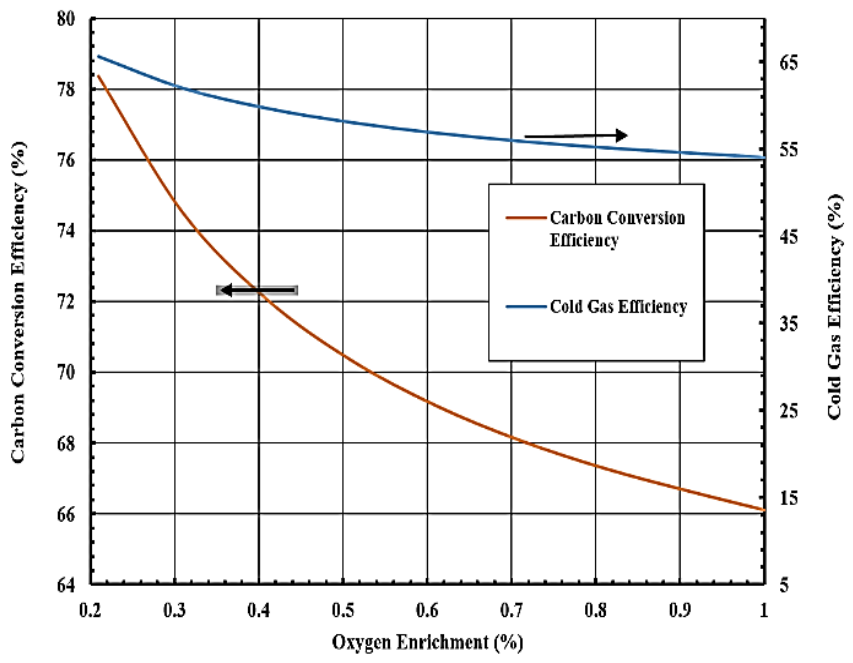

Figure 6. Changes in the number of moles of gaseous components produced relative to changes in the oxygen enrichment of the input. 


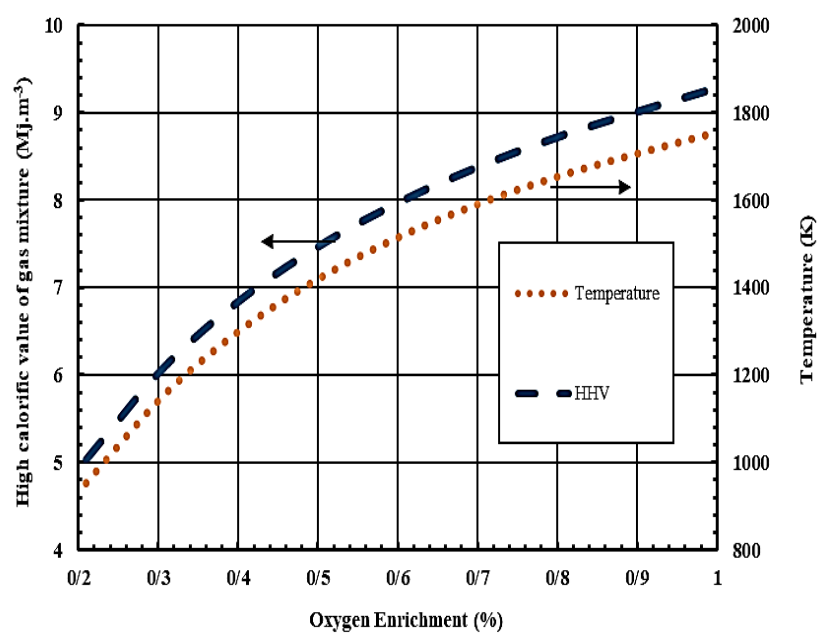

Figure 7. Changes in temperature and high calorific value of the gas mixture relative to changes in oxygen enrichment.

According to the introduction part, some amount of fuel is partially combusted to provide the necessary heat for gasification and temperature resulting from combusting with pure oxygen will be higher than with air due to the presence of nitrogen in the gas mixture which acts like a heat sink. Hence in the absence of nitrogen the temperature of gas mixture will be higher as it is shown in Figure 7.

Increasing the volume percentage of gaseous components such as hydrogen and carbon monoxide increases the high calorific value of the produced gas which according to Figure 7 its value will increase from $5{\mathrm{MJ} . \mathrm{m}^{-3}}^{-3}$ in air gasification to $9.28 \mathrm{MJ} . \mathrm{m}^{-3}$ in pure oxygen gasification. Figure 8 indicates that with increasing oxygen enrichment and decreasing nitrogen, the volume percentage of hydrogen and carbon monoxide are increased and there is no need to spend money for separating nitrogen from gas mixture and purify it.

This gas mixture in the combustion chamber will produce less $\mathrm{NO}_{\mathrm{x}}$, which will be beneficial to the environment and this is another advantage of increasing the presence of oxygen in the gasifier agent.

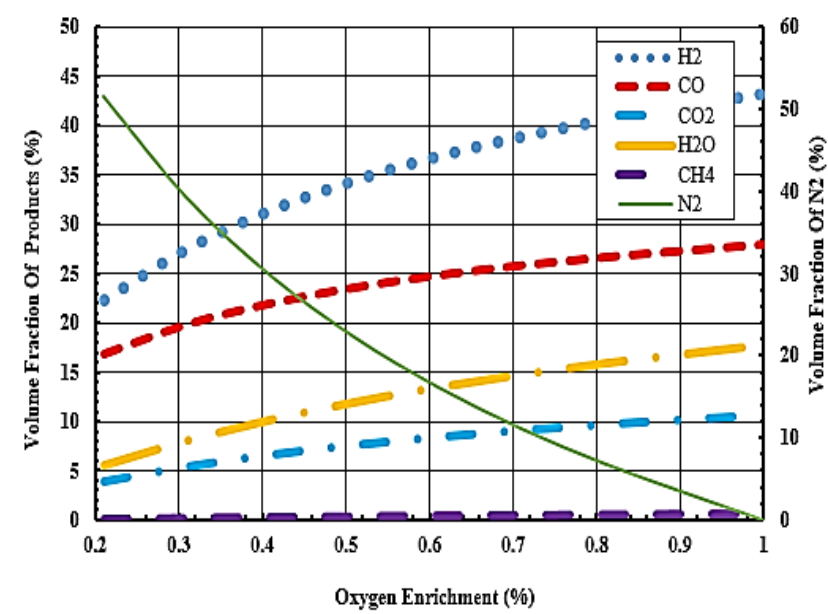

Figure 8. Changes in the volume fraction of the gas components produced relative to changes in oxygen enrichment.

\subsection{Pressure change}

Pressure changes in the gasification process have also been studied. For this purpose, the parameters of equivalence ratio and inlet temperature are 0.4 and $298 \mathrm{~K}$ and pure oxygen is gasification agent. Due to the small molar changes in the gas mixture components compared to the pressure changes, these changes are logarithmically shown in Figure 9. for better observation. According to the diagram, the molar amount of hydrogen and carbon monoxide is slightly decreasing and the moles of methane, carbon dioxide and water vapor are increasing. This phenomenon can be expressed according to the Le Chatelier's principle that in equilibrium reactions with increasing in pressure, the reaction goes to direction that has less moles of gas to maintain the equilibrium so the methane reforming reaction is shifted to the left and subtracted from the molar amount of hydrogen and carbon monoxide and added to the amount of water vapor and methane. Also, by adding moles of water vapor to the water-gas reaction, this reaction will shift towards the consumption of the added moles of gas and the moles of carbon monoxide and water vapor will be reduced and the moles of carbon dioxide and hydrogen will be increased. In total, the effect of these two phenomena and according to the diagram, the mole number of carbon monoxide and hydrogen will decrease slightly and the mole number of carbon dioxide, water vapor and methane will increase slightly.

The amount of changes in the calorific value of the produced gas and the cold gas efficiency are plotted in Figure 10. Due to the reduction of the molar fraction of hydrogen and carbon monoxide, the calorific value of the produced gas mixture is expected to decrease, but it should be noted that increasing the molar fraction of methane will neutralize the effect of reducing hydrogen and carbon monoxide. Hence, the higher calorific value will increase slightly and changes from $10.8803 \mathrm{MJ} . \mathrm{m}^{-3}$ to $10.886 \mathrm{MJ} . \mathrm{m}^{-3}$. The cold gas efficiency has very slight change which is due to the small changes in the moles of the produced gases.

As mentioned in pressure change, according to the Le Chatelier's principle, chemical reactions to maintain equilibrium are moved to a direction that has less gas moles, so the methane reforming reaction is shifted to the left and will be exothermic reaction, this will increase the temperature of the gas mixture, which can be seen in Figure 11.

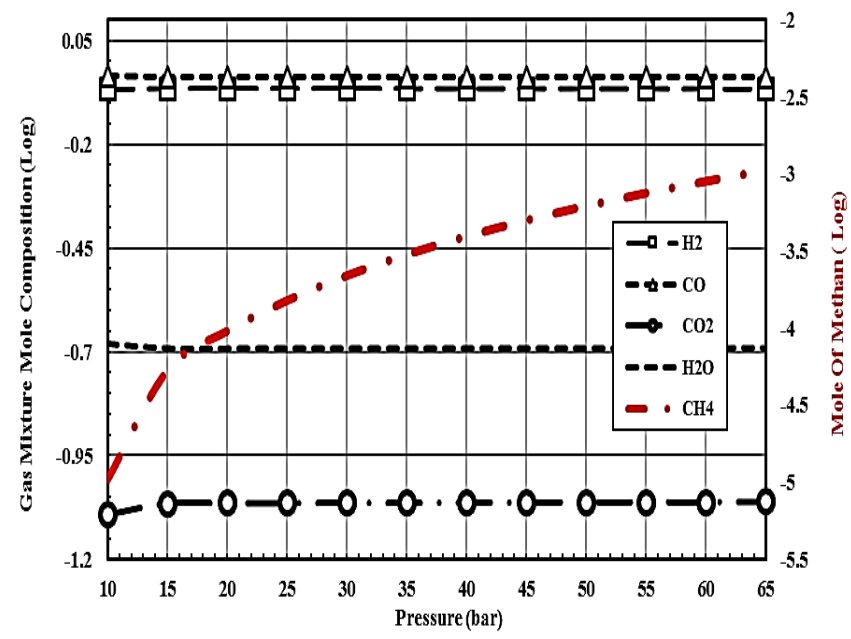

Figure 9. Changes in the volume percentage of the components of the produced gas mixture compared to the changes in pressure in the logarithmic state.

The results show that pressure changes will have negligible effect on the molar percentages of gases as well as on energy efficiency, but it should be noted that this increase 
in pressure can have good economic benefits. As the exhaust gas pressure increases there will be no need for a compressor to increase the pressure. It should be noted that the gas mixture must be pressurized for use in subsequent processes such as burning in a gas turbine or participating in a chemical process and for chemical processes a minimum pressure of 10 atmospheres is required.

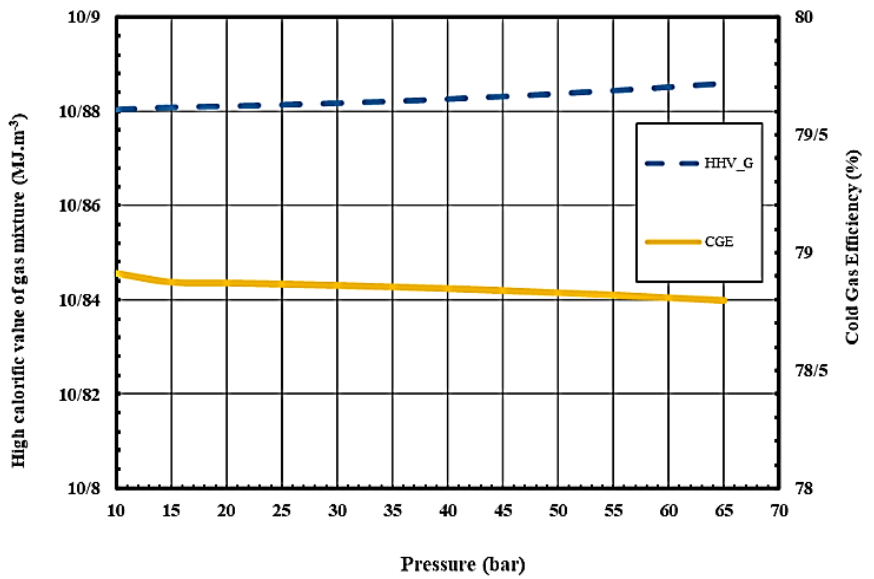

Figure 10. Changes in cold gas efficiency and calorific value of produced gas relative to pressure changes.

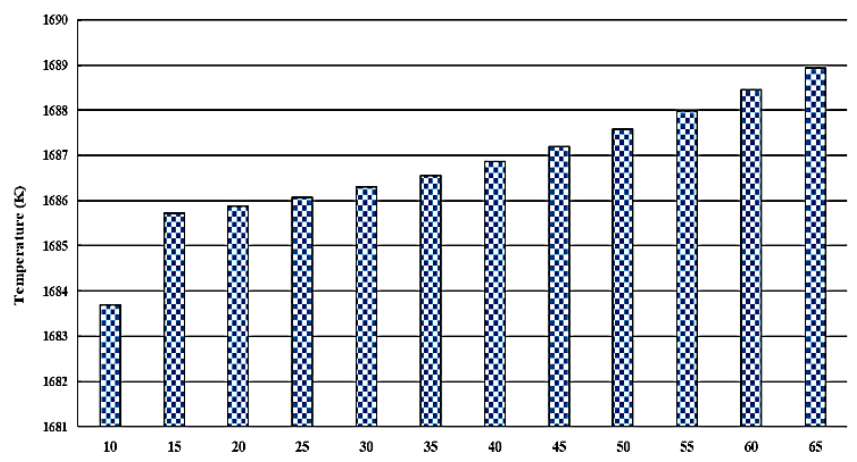

Figure 11. Changes in gas mixture temperature relative to changes in gasification pressure.

\subsection{The ratio of hydrogen to carbon monoxide}

In this section, changes in the ratio of hydrogen to carbon monoxide with respect to changes in the equivalence ratio, pressure and oxygen enrichment are investigated. Figure 12 shows that with changes in the equivalence ratio, the amount of $\mathrm{H}_{2}$ : $\mathrm{CO}$ decreases, this can be clear because by increasing the equivalence ratio, the gasification process approaches combustion and the amount of hydrogen production decreases sharply, according to Figure 2, this reduction will be much greater than the reduction of carbon monoxide therefore it is expected that the $\mathrm{H}_{2}$ : $\mathrm{CO}$ ratio will also decrease. By changing the oxygen enrichment the amount of carbon monoxide in the gas mixture decreases and the $\mathrm{H}_{2}$ :CO ratio will also increase. It can also be seen that with changes in pressure, the ratio of hydrogen to carbon monoxide will not change much because with increasing pressure, the volume percentage of the components of the exhaust gas mixture change slightly. The quality of the exhaust gas mixture is usually measured by the $\mathrm{H}_{2}$ : $\mathrm{CO}$ ratio, and high quality gas can be used in chemical processes such as methanol production.

Also, by separating hydrogen from the gas mixture, it can be used as fuel in fuel cells. The higher the quality of the gas mixture, the easier this separation will be. According to Figure 12. it can be concluded that waste engine oil gasification will have a high potential for use in downstream chemical processes or in fuel cells. For this purpose, the value of equivalence ratio of 0.3 and $100 \%$ oxygen enrichment and arbitrary pressure will be the best values for high $\mathrm{H}_{2}$ : $\mathrm{CO}$ ratio.

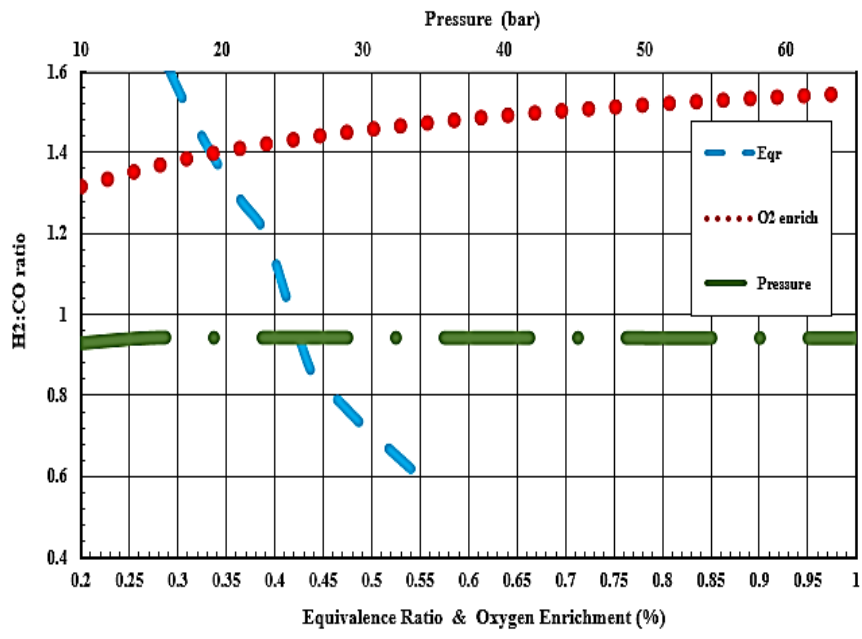

Figure 12. Changes in the ratio of $\mathrm{H}_{2}$ : $\mathrm{CO}$ for changes in the equivalence ratio and gasification pressure.

\section{Conclusion}

A numerical algorithm based on the thermochemical equilibrium approach was developed to simulate the waste oil gasification process. This model can predict the distribution of synthetic gas species produced in real gasification operating conditions. This model was confirmed by comparing numerical results with experimental results.

Through a parametric study it was shown that the gasification of waste oil with an equivalence ratio of 0.4 to 0.42 makes it possible to produce a synthesis gas with a significant calorific value of about $10 \mathrm{MJ} . \mathrm{m}^{-3}$. Gas mixture with such a calorific value are suitable for applications such as gas turbines that consume high calorific value gases. The use of pure oxygen as a gasification agent leads to the production of a high calorific value and a hydrogen-rich gas mixture with a hydrogen content of $43 \%$ by volume and $\mathrm{H}_{2}$ :CO ratio of about 1.6. Gas mixture with such a high $\mathrm{H}_{2}$ : $\mathrm{CO}$ ratio can be used in the methanol synthesis process and in the production of pure hydrogen for fuel cell applications. The parametric study also showed that the gasification pressure does not have a significant effect on the gasification properties. Simulations performed during this study show that gasification of waste oil is a possible process that can be used to produce synthetic gas for various industrial applications. The developed numerical model can be used to design and optimize such gasifiers. 


\section{Nomenclature}

$\alpha, \beta, z$ numbers of atoms of hydrogen, oxygen, and nitrogen per one atom of carbon in the feedstock; respectively

$h_{f . i}^{0}$

$\mathrm{w}, \mathrm{m}, \mathrm{s}$ feedstock, respectively

$\mathrm{m}_{\mathrm{h}} \quad$ the mass fraction of hydrogen in dry fuel analyses

$\mathrm{x}_{\mathrm{i}} \quad$ the mole number of species $\mathrm{i}$

$\mathrm{M}_{\text {fuel }} \quad$ the molar mass of the heavy fuel oil

$\mathrm{M}_{\text {water }}$ the molar mass of water

wc the mass-based water content of the feedstock

$n_{t} \quad$ the total number of moles of produced gas

$\mathrm{K}$ equilibrium constant

$\mathrm{R}_{\mathrm{u}} \quad$ the universal gas constant

$\eta_{C G} \quad$ cold gas efficiency

$\eta_{C C E} \quad$ the carbon conversion efficiency

$\mathrm{P}$ the pressure of gas mixture (bar)

$h_{f g} \quad$ the enthalpy of vaporization of water

$C_{p} \quad$ the specific heat at constant pressure

$\Delta h \quad$ the enthalpy difference between any given state and

$\Delta h \quad$ the reference state

$m_{c} \quad$ the mass fraction of carbon in the dry fuel analyses

\section{Appendix A. Gasification modeling equations}

The following equations can be used to determine the fuel's chemical formula based on the mass fraction of its constituent components. $\alpha, \beta, \mathrm{z}$ represents molar ratio of hydrogen, oxygen and nitrogen to carbon in the fuel in dry state.

$\alpha=\frac{\left(m_{h} \times M_{c}\right)}{\left(m_{c} \times M_{h}\right)}$

$\beta=\frac{\left(m_{o} \times M_{c}\right)}{\left(m_{c} \times M_{o}\right)}$

$z=\frac{\left(m_{N} \times M_{c}\right)}{\left(m_{c} \times M_{N}\right)}$

$\mathrm{M}_{\mathrm{i}}$ and $\mathrm{m}_{\mathrm{i}}$ are the molar mass and dry mass fraction of each element respectively. The ratio of moles of moisture to each moles of fuel is obtained by the following equation:

$\mathrm{w}=\left(\mathrm{M}_{\text {fuel }} \times \mathrm{wc}\right) /\left(\mathrm{M}_{\text {water }} \times(1-\mathrm{wc})\right)$

$w c$ is the mass fraction of moisture in the fuel. $M_{w a t e r}$ and $\mathrm{M}_{\text {fuel }}$ are the molecular masses of water and fuel, respectively. The amount of air required for complete combustion of a fuel with the chemical formula $\mathrm{CH}_{\alpha} \mathrm{O}_{\beta} \mathrm{N}_{z}$ is obtained from the following equation, which is also called stoichiometric air:

Sto $=1+(0.25 \alpha)-(0.5 \beta)$

In gasification, the amount of air required is less than the amount of air needed for incomplete combustion and equal to a factor of the stoichiometric air demand (Sto). This coefficient varies between 0.3 and 0.6 , which is the equivalence ratio.

$m=e q r \times$ Sto

According to the mass conservation law for the three elements carbon, hydrogen and oxygen, three equations are
$\mathrm{C}, \mathrm{H}, \mathrm{O}, \mathrm{N}, \mathrm{S}$

carbon, hydrogen, oxygen, nitrogen, sulfur, contents of feedstock, respectively

the enthalpy/heat of formation for species i

$h_{\text {fuel }}^{0}$

the enthalpy formation of fuel

$\Delta h_{f}^{0} \quad$ the change of formation's enthalpy for a

reaction

HHV higher heating value

$H H V_{\text {fuel }} \quad$ higher heating value of fuel

$L H V_{\text {fuel }} \quad$ lower heating value of fuel

$\Delta G^{0} \quad$ the standard Gibbs function of formation

$\mathrm{J}$ the constant of integration

I a constant

$\mathrm{A}, \mathrm{B}, \mathrm{C}$, and $\mathrm{D}$ the coefficients for determining the specific

$\mathrm{T} \quad$ temperature

M equivalence ratio

Sto stoichiometric air for complete combustion

Sto of the fossil fuel

$E_{p g} \quad$ the energy of produced gas

$E_{\text {feed }}$

the energy of inlet fuel

obtained from the equations needed to find the unknown gaseous moles.

$1=x_{2}+x_{3}+x_{5}+x_{6}$

$\alpha+2 w+2 s=2 x_{1}+2 x_{4}+4 x_{5}$

$\beta+w+s+2 m=x_{2}+2 x_{3}+x_{4}$

The equilibrium constant equation is defined by the following formula [13]:

$K=\prod_{i}\left(x_{i}^{v_{i}}\right) \times\left(\frac{P}{n_{t}}\right)^{\sum_{i} v_{i}}$

$\mathrm{x}_{\mathrm{i}}$ is gas mole in the reaction, $\mathrm{v}_{\mathrm{i}}$ stoichiometric coefficients, $\mathrm{P}$ total pressure gasification and $\mathrm{n}_{\mathrm{t}}$ is total gas moles. The equilibrium constant for each reactions in this paper will be obtained as follows:

$K_{1}=\frac{x_{2}^{2}}{x_{3}}\left(\frac{P}{n_{t}}\right)^{1}$

$K_{2}=\frac{x_{2} x_{1}}{x_{4}}\left(\frac{P}{n_{t}}\right)^{1}$

$K_{3}=\frac{x_{5}}{x_{1}{ }^{2}}\left(\frac{P}{n_{t}}\right)^{-1}$

$K_{4}=\frac{x_{3} x_{1}}{x_{2} x_{4}}\left(\frac{P}{n_{t}}\right)^{0}$

$K_{5}=\frac{x_{2} x_{1}{ }^{3}}{x_{5} x_{4}}\left(\frac{P}{n_{\text {tot }}}\right)^{2}$

The chemical equilibrium constant of each reaction will have the following correlation with the free standard Gibbs energy:

$\ln K=-\frac{\Delta G^{0}}{R_{u} T}$ 
The parameter $\mathrm{T}$ and $\mathrm{R}_{\mathrm{u}}$ are the outlet temperature of the gasification reactor and the universal constant of gases respectively. The dependence of Gibbs free energy on temperature is given in the following equation:

$\frac{d\left(\frac{\Delta G^{0}}{R_{u} T}\right)}{d t}=-\frac{\Delta h_{f}^{0}}{R_{u} T^{2}}$

$\frac{d(\ln K)}{d t}=\frac{\Delta h_{f}^{0}}{R_{u} T^{2}}$

Since $\Delta h_{f}$ is a function of temperature, it can be integrated as follows:

$\ln K=\left(\int \frac{\Delta h_{f}^{0}}{R_{u} T^{2}} d T\right)+\mathrm{I}$

"I" in the above formula is the constant of integration. The amount of enthalpy and heat capacity will be linked by the following formula:

$\mathrm{h}=\left(\int C_{p} d T\right)$

Heat capacity is obtained by having the temperature by the following equation [14]:

$C_{p}=R_{u}\left(A+B T+C T^{2}-D T^{-2}\right)$

The coefficients A, B, C, D are in Table A1 and the enthalpy is:

$h=R_{u}\left(A T+\frac{B}{2} T^{2}+\frac{C}{3} T^{3}-\frac{D}{T}\right)+j$

Table A1. Constants A, B, C, D for calculating heat capacity [14].

\begin{tabular}{cccccc}
\hline $10^{-5} \mathrm{D}$ & $10^{6} \mathrm{C}$ & $10^{3} \mathrm{~B}$ & $\mathrm{~A}$ & $\mathrm{~T}($ Kelvins $)$ & $\begin{array}{c}\text { Chemical } \\
\text { Formula }\end{array}$ \\
\hline 0.083 & - & 0.422 & 3.249 & $\begin{array}{c}298.15 \text { to } \\
3000\end{array}$ & $\mathrm{H}_{2}$ \\
-0.031 & - & 0.557 & 3.376 & $\begin{array}{c}298.15 \text { to } \\
2500\end{array}$ & $\mathrm{CO}$ \\
-1.157 & - & 1.045 & 5.457 & $\begin{array}{c}298.15 \text { to } \\
2000\end{array}$ & $\mathrm{CO}_{2}$ \\
0.121 & - & 1.450 & 3.470 & $\begin{array}{c}298.15 \text { to } \\
2000\end{array}$ & $\mathrm{H}_{2} \mathrm{O}$ \\
& & & & $\begin{array}{c}298.15 \text { to } \\
1500\end{array}$ & $\mathrm{CH}_{4}$ \\
-0.867 & - & 0.771 & 1.771 & $\begin{array}{c}298.15 \text { to } \\
2000\end{array}$ & $\mathrm{C}$ \\
\hline
\end{tabular}

The difference in enthalpies of a particular reaction is obtained as follows:

$$
\begin{aligned}
& \Delta h=R_{u}\left(\Delta A T+\frac{\Delta B}{2} T^{2}+\frac{\Delta C}{3} T^{3}-\frac{\Delta D}{T}\right)+J \\
& \ln \mathrm{K}=\Delta \mathrm{A} \ln \mathrm{T}+\Delta \mathrm{B} \frac{\mathrm{T}}{2}+\frac{\Delta \mathrm{C}}{6} \mathrm{~T}^{2}-\frac{\Delta \mathrm{D}}{2 \mathrm{~T}^{2}}+\mathrm{I}-\frac{\mathrm{J}}{\mathrm{R}_{\mathrm{u}} \mathrm{T}} \\
& \mathrm{K}=\exp \left(\Delta A \ln T+\Delta B \frac{T}{2}+\frac{\Delta C}{6} T^{2}-\frac{\Delta D}{2 T^{2}}+I-\frac{J}{R_{u} T}\right)
\end{aligned}
$$

$$
\Delta G^{0}=-R_{u} T\left(\Delta A \ln T+\Delta B \frac{T}{2}+\frac{\Delta C}{6} T^{2}-\frac{\Delta D}{2 T^{2}}+I-\frac{J}{R_{u} T}\right)
$$

Table A2. Gibbs free energy and the enthalpy of formation of each reaction at $298 \mathrm{~K}$.

\begin{tabular}{ccc}
\hline $\begin{array}{c}\text { Gibbs Free Energy of } \\
\text { Formation }\left(\mathrm{kJ}_{\mathrm{kmol}}{ }^{-1}\right)\end{array}$ & $\begin{array}{c}\text { Standard Enthalpy of } \\
\text { Formation }\left(\mathrm{kJ}^{\mathrm{kmol}}{ }^{-1}\right)\end{array}$ & $\begin{array}{c}\text { Chemical } \\
\text { Formula }\end{array}$ \\
\hline 0 & 0 & $\mathbf{H}_{\mathbf{2}}$ \\
-137169 & -110525 & $\mathrm{CO}$ \\
-394359 & -393509 & $\mathbf{C O}_{\mathbf{2}}$ \\
-228572 & -241818 & $\mathbf{H}_{\mathbf{2}} \mathbf{0}$ \\
-50460 & -74520 & $\mathbf{C H}_{\mathbf{4}}$ \\
0 & 0 & $\mathrm{C}$ \\
\hline
\end{tabular}

I and $\mathrm{J}$ constants are determined by identifying the Gibbs free energy and enthalpy of formation for each reactions at 298K (Table A2).

\section{References:}

[1] M. N. Nasim, M. Sohail, B. Ravindra, V. J. J. o. M. Lotia, and $\mathrm{C}$. Engineering, "Recycling waste automotive engine oil as alternative fuel for diesel engine: A review," pp. 46-50, 2014.

[2] K. K. Ramasamy and T. J. C. T. Ali, "Hydrogen production from used lubricating oils," vol. 129, no. 3-4, pp. 365-371, 2007.

[3] M. Fuentes, R. Font, M. Gómez-Rico, I. J. J. o. A. Martín-Gullón, and A. Pyrolysis, "Pyrolysis and combustion of waste lubricant oil from diesel cars: Decomposition and pollutants," vol. 79 , no. 1-2, pp. 215226, 2007.

[4] M. Rosli, F. Yee, and S. S. Tea, "Modeling and simulation of used lubricant oil re-refining process," in 2nd World Engineering Congress, Sarawak, Malaysia, 2002.

[5] N. Selukar and S. J. I. J. o. A. C. Wagh, "Gasoline and diesel synthesis from waste lubricating oil: A kinetic approach," pp. 22-25, 2014.

[6] F. C.-Y. Wang, L. J. E. Zhang, and fuels, "Chemical composition of group II lubricant oil studied by highresolution gas chromatography and comprehensive twodimensional gas chromatography," vol. 21, no. 6, pp. 3477-3483, 2007.

[7] E. M. Fujita, D. E. Campbell, and B. J. F. R. Zielinska, Desert Research Institute, Reno, Nevada, USA, "Chemical analysis of lubrication oil samples from a study to characterize exhaust emissions from light-duty gasoline vehicles in the Kansas City Metropolitan Area," 2006.

[8] J. Moore, S. Cui, P. Cummings, and H. J. A. I. o. C. E. A. J. Cochran, "Lubricant characterization by molecular simulation," vol. 43, no. 12, p. 3260, 1997.

[9] J. Sharaf, B. Mishra, R. J. I. J. o. E. R. Sharma, and Applications, "Production of gasoline-like fuel obtained 
from waste lubrication oil and its physicochemical properties," vol. 3, no. 3, pp. 113-118, 2013.

[10] S. S. Lam et al., "Progress in waste oil to sustainable energy, with emphasis on pyrolysis techniques," vol. 53, pp. 741-753, 2016.

[11] M. Puig-Arnavat, J. C. Bruno, A. J. E. Coronas, and Fuels, "Modified thermodynamic equilibrium model for biomass gasification: a study of the influence of operating conditions," vol. 26, no. 2, pp. 1385-1394, 2012.

[12] M. Puig Arnavat, "Performance modelling and validation of biomass gasifiers for trigeneration plants," Universitat Rovira i Virgili, 2011.

[13] L. Chanphavong and Z. J. J. o. t. E. I. Zainal, "Characterization and challenge of development of producer gas fuel combustor: A review," vol. 92, no. 5, pp. 1577-1590, 2019.

[14] G. Gautam, "Parametric study of a commercial-scale biomass downdraft gasifier: experiments and equilibrium modeling," 2010.

[15] C. Higman and M. v. der Burgt, "Gasification. 2nd," 2008.

[16] A. K. J. E. C. Sharma and Management, "Modeling and simulation of a downdraft biomass gasifier 1. Model development and validation," vol. 52, no. 2, pp. 13861396, 2011.

[17] M. Puig-Arnavat, J. A. Hernández, J. C. Bruno, A. J. B. Coronas, and bioenergy, "Artificial neural network models for biomass gasification in fluidized bed gasifiers," vol. 49, pp. 279-289, 2013.

[18] P. Basu, Biomass gasification and pyrolysis: practical design and theory. Academic press, 2010.

[19] M. Puig-Arnavat, J. C. Bruno, A. J. R. Coronas, and s. e. reviews, "Review and analysis of biomass gasification models," vol. 14, no. 9, pp. 2841-2851, 2010.

[20] S. Vakalis, F. Patuzzi, and M. J. B. t. Baratieri, "Thermodynamic modeling of small scale biomass gasifiers: Development and assessment of the "MultiBox'”approach," vol. 206, pp. 173-179, 2016.

[21] A. J. F. Bridgwater, "The technical and economic feasibility of biomass gasification for power generation," vol. 74, no. 5, pp. 631-653, 1995.

[22] M. Baratieri, P. Baggio, L. Fiori, and M. J. B. t. Grigiante, "Biomass as an energy source: thermodynamic constraints on the performance of the conversion process," vol. 99, no. 15, pp. 7063-7073, 2008.

[23] M. J. Prins, K. J. Ptasinski, and F. J. J. E. Janssen, "From coal to biomass gasification: Comparison of thermodynamic efficiency," vol. 32, no. 7, pp. 12481259, 2007.

[24] A. K. J. E. C. Sharma and Management, "Equilibrium modeling of global reduction reactions for a downdraft (biomass) gasifier," vol. 49, no. 4, pp. 832-842, 2008.

[25] L. Shen, Y. Gao, J. J. B. Xiao, and bioenergy, "Simulation of hydrogen production from biomass gasification in interconnected fluidized beds," vol. 32, no. 2 , pp. $120-127,2008$.
[26] A. Mountouris, E. Voutsas, D. J. E. C. Tassios, and Management, "Solid waste plasma gasification: equilibrium model development and exergy analysis," vol. 47, no. 13-14, pp. 1723-1737, 2006.

[27] S. Jarungthammachote and A. Dutta, "Thermodynamic equilibrium model and second law analysis of a downdraft waste gasifier," Energy, vol. 32, no. 9, pp. 1660-1669, 2007.

[28] M. Ashizawa, S. Hara, K. Kidoguchi, and J. Inumaru, "Gasification characteristics of extra-heavy oil in a research-scale gasifier," Energy, vol. 30, no. 11-12, pp. 2194-2205, 2005.

[29] S.-M. Beheshti, H. Ghassemi, R. J. P. s. ShahsavanMarkadeh, and technology, "A comprehensive study on gasification of petroleum wastes based on a mathematical model," vol. 32, no. 22, pp. 2674-2681, 2014.

[30] S.-M. Beheshti, H. Ghassemi, R. J. P. S. ShahsavanMarkadeh, and Technology, "Modeling Steam Gasification of Orimulsion in the Presence of $\mathrm{KOH}$ : A Strategy for High-Yield Hydrogen Production," vol. 33, no. 2, pp. 218-225, 2015.

[31] M. S. B. Khaleghi, R. S. Markadeh, H. J. P. S. Ghassemi, and Technology, "Thermodynamic evaluation of mazut gasification for using in power generation," vol. 34, no. 6, pp. 531-538, 2016.

[32] Y. Castillo Santiago, A. Martínez González, O. J. Venturini, and D. M. Yepes Maya, "Assessment of the energy recovery potential of oil sludge through gasification aiming electricity generation," Energy, vol. 215 , p. 119210, 2021/01/15/ 2021.

[33] D. Vera, B. de Mena, F. Jurado, and G. Schories, "Study of a downdraft gasifier and gas engine fueled with olive oil industry wastes," Applied Thermal Engineering, vol. 51, no. 1, pp. 119-129, 2013/03/01/ 2013.

[34] A. M. Sanchez-Hernandez, N. Martin-Sanchez, M. J. Sanchez-Montero, C. Izquierdo, and F. Salvador, "Different options to upgrade engine oils by gasification with steam and supercritical water," The Journal of Supercritical Fluids, vol. 164, p. 104912, 2020/10/01/ 2020.

[35] N. Couto et al., "Numerical and experimental analysis of municipal solid wastes gasification process," Applied Thermal Engineering, vol. 78, pp. 185-195, 2015/03/05/ 2015.

[36] M. Ruggiero and G. J. R. e. Manfrida, "An equilibrium model for biomass gasification processes," vol. 16, no. 14, pp. 1106-1109, 1999.

[37] A. Melgar, J. F. Pérez, H. Laget, A. J. E. c. Horillo, and management, "Thermochemical equilibrium modelling of a gasifying process," vol. 48, no. 1, pp. 59-67, 2007.

[38] C. R. Altafini, P. R. Wander, R. M. J. E. C. Barreto, and Management, "Prediction of the working parameters of a wood waste gasifier through an equilibrium model," vol. 44, no. 17, pp. 2763-2777, 2003.

[39] M. Lapuerta, J. J. Hernández, F. V. Tinaut, and A. Horrillo, "Thermochemical behaviour of producer gas from gasification of lignocellulosic biomass in SI engines," SAE Technical Paper0148-7191, 2001. 
[40] G. Schuster, G. Löffler, K. Weigl, and H. J. B. t. Hofbauer, "Biomass steam gasification-an extensive parametric modeling study," vol. 77, no. 1, pp. 71-79, 2001.

[41] T. Jayah, R. Fuller, L. Aye, and D. J. I. E. J. Stewart, "The potential for wood gasifiers for tea drying in Sri Lanka," vol. 2, no. 2, 2007.

[42] C. J. C. e. s. Di Blasi, "Dynamic behaviour of stratified downdraft gasifiers," vol. 55, no. 15, pp. 2931-2944, 2000.

[43] M. Rao, S. Singh, M. Sodha, A. Dubey, M. J. B. Shyam, and Bioenergy, "Stoichiometric, mass, energy and exergy balance analysis of countercurrent fixed-bed gasification of post-consumer residues," vol. 27, no. 2, pp. 155-171, 2004.

[44] S. Channiwala and P. J. F. Parikh, "A unified correlation for estimating HHV of solid, liquid and gaseous fuels," vol. 81, no. 8, pp. 1051-1063, 2002.

[45] I. P. Silva, R. M. Lima, G. F. Silva, D. S. Ruzene, D. P. J. R. Silva, and S. E. Reviews, "Thermodynamic equilibrium model based on stoichiometric method for biomass gasification: A review of model modifications," vol. 114, p. 109305, 2019.

[46] H. Ghassemi, R. J. E. C. Shahsavan-Markadeh, and Management, "Effects of various operational parameters on biomass gasification process; a modified equilibrium model," vol. 79, pp. 18-24, 2014.

[47] M. Vaezi, M. Passandideh-Fard, M. Moghiman, and M. Charmchi, "Gasification of heavy fuel oils: A thermochemical equilibrium approach," Fuel, vol. 90, no. 2, pp. 878-885, 2011.

[48] H. Ghassemi, S. Beheshti, and R. J. F. ShahsavanMarkadeh, "Mathematical modeling of extra-heavy oil gasification at different fuel water contents," vol. 162, pp. 258-263, 2015.

[49] K. Lin, S. Chowdhury, C. Shen, and C. Yeh, "Hydrogen generation by catalytic gasification of motor oils in an integrated fuel processor," Catalysis Today, vol. 136, no. 3-4, pp. 281-290, 2008. 